\title{
A saúde de quem está em situaçâo de rua: (in)visibilidades no acesso ao Sistema Único de Saúde
}

I ${ }^{1}$ Fabiana Aparecida Almeida Lawall Valle, ${ }^{2}$ Beatriz Francisco Farah I

Resumo: O acesso ao Sistema Único de Saúde é pressuposto para a dignidade da populaçáo em situação de rua, que pela vulnerabilidade social é exposta a fatores que interferem na saúde. Objetivo: compreender como é o acesso ao Sistema Único de Saúde na percepção dos adultos em situação de rua. Abordagem metodológica qualitativa, com estudo descritivo exploratório. As técnicas utilizadas foram: entrevistas individuais semiestruturadas, observação e diário de campo. Participaram 20 pessoas em situação de rua. As informaçôes foram analisadas à luz da Hermenêutica Dialética. O acesso aos serviços de saúde ocorreu pelas situações de urgência e emergência e na Atenção Básica era limitado, sendo ofertadas duas vagas semanais a essa população, em uma única Unidade Básica de Saúde. Os acessos aconteceram com mediação dos equipamentos da rede de proteção social ou do Consultório na Rua cerceando o acesso dos cidadáos aos serviços de saúde. Foram barreiras para o acesso: necessidade da apresentação de documentos e comprovação de residência. Muitos são os desafios. A saúde é direito de todos, e seu acesso deve ser uma realidade.

> Palavras-chave: pessoas em situação de rua; acesso à saúde; serviços de saúde.
${ }^{1}$ Universidade Federal de Juiz de Fora. Juiz de Fora-MG, Brasil (fabiana.lawall@gmail.com). ORCID: 0000-0001-7785-8310

${ }^{2}$ Universidade Federal de Juiz de Fora. Juiz de Fora-MG, Brasil (b-farah@hotmail.com). ORCID: 0000-0002-3345-0601
Recebido em: 24/08/2019 Aprovado em: 13/01/2020 Revisado em: 30/06/2020 


\section{Introdução}

No Brasil muitas foram as lutas para que a questão social fosse admitida como responsabilidade coletiva. A saúde foi instituída como direito em 1988 a partir da promulgação da Constituiçáo Federal (CF/88). Estava determinado que todo e qualquer cidadáo tem direito a acessar a todos os serviços públicos de saúde, independentemente de gênero, idade, classe econômica, sem sofrer preconceitos de qualquer espécie. A saúde tornou-se direito universal (BRASIL, 1988).

A efetivação do direito à saúde e a conquista de suas metas caminham por um percurso árduo, cheio de inevitáveis reflexôes. A compreensão do acesso da população ao Sistema Único de Saúde (SUS) torna-se instrumento de luta para o atendimento das necessidades de saúde da população. Acesso este entendido como um conceito multifacetado, que envolve dimensões: política, econômica-social, organizativa, técnica e simbólica (ASSIS; JESUS, 2012). No presente artigo optou-se por discutir o acesso através do uso dos serviços: quais serviços são utilizados, por quais motivos e quais as barreiras encontradas.

Os passos estabelecidos pelas políticas públicas para a população em situação de rua ainda são tímidos, mas é inegável que a construção da Política Nacional para a População em Situação de Rua (PNPSR), publicada em 2009, foi um avanço para a superação da invisibilidade social que acompanha este grupo (BOVE; FIGUEIREDO, 2016). A política caracteriza a população em situação de rua como um grupo heterogêneo, que possui os laços familiares interrompidos ou fragilizados, que vivencia a situação de pobreza extrema e se utiliza dos espaços públicos como moradia (BRASIL, 2009).

A PNPSR instituiu algumas diretrizes importantes para atender às necessidades específicas das pessoas em situação de rua, como trabalho, desenvolvimento urbano, assistência social, educação, segurança alimentar e nutricional, cultura e saúde (BRASIL, 2009). A garantia de acesso aos serviços públicos, incluindo os serviços de saúde, compóe uma de suas diretrizes. Diante disso, é necessário refletir que apesar de a saúde ter sido instituída como direito universal pela Constituição Federal em 1988, o acesso ao SUS pelas populaçôes mais vulneráveis, com adequaçáo dos serviços e açóes existentes, ainda deve ser visto com um olhar mais atento, na perspectiva da promoção da equidade. 
O acesso da população em situação de rua aos serviços e açôes de saúde é um pressuposto essencial para a dignidade desse grupo, que, pela vulnerabilidade social, é exposto a vários fatores que interferem na saúde. Dormir ao relento, a exposição às variaçóes climáticas, a falta de alimentação e nutrição adequadas, e a vivência do preconceito e da discriminação são fatores que podem determinar as condições de saúde (AGUIAR; IRIART, 2012; BARATA et al., 2015; CAMPBELL et al., 2015; FARIAS et al., 2014). Tais fatores demandam respostas técnicas, gerenciais e de políticas setoriais e, sobretudo, as de natureza intersetorial.

Atualmente, o Brasil passa por uma crise econômica e política que produz efeitos nos diferentes setores da sociedade, aumentando as desigualdades sociais (LARA; GUARESCHI; BERNARDES, 2016). Com o aumento das desigualdades sociais, aumenta-se o número de pessoas que necessitam de proteção social, incluindo o acesso aos mais diversos serviços públicos, como os serviços de saúde. As atuais propostas de governo atingem profundamente o SUS, ameaçando seu aspecto universal, a despeito da garantia constitucional. Com a justificativa de que o sistema de saúde brasileiro e a universalidade preconizada pela $\mathrm{CF} / 88$ não cabem no orçamento público, pretende-se converter o SUS em um sistema residual. O risco é o estabelecimento de um sistema precário para a população que mais necessita (PAIVA et al., 2016).

Sobre as propostas e decisões recentemente tomadas pelo Ministério da Saúde, Cohn (2016) ressalta o "desconhecimento" da equipe do atual governo sobre os aspectos que circundam a pobreza, fato que, consequentemente, fortalece discursos carregados de preconceitos. A culpabilização dos pobres por seu estado de pobreza reaparece nas falas produzidas pelo governo. E é com tal desconhecimento que se enuncia que a redução de gastos com a área social traz consigo a salvação da economia (COHN, 2016; PAIVA et al., 2016; RIZZOTO, 2016). Com o atual cenário político, econômico e social brasileiro, torna-se essencial provocar o debate sobre o acesso ao SUS pelas populaçôes mais vulneráveis, levando-se em consideração a possibilidade de fortalecimento do SUS e contribuição para melhorias dos serviços prestados.

Diante do exposto, o objetivo geral da pesquisa foi compreender como é o acesso ao Sistema Único de Saúde na percepção dos adultos em situação de rua em um município da Zona da Mata Mineira. As questôes norteadoras buscaram responder as seguintes perguntas: a população em situação de rua tem acesso aos serviços de saúde? Em quais circunstâncias este acesso acontece? 
A presente pesquisa foi resultado da dissertaçâo de mestrado apresentada ao Programa de Pós-graduação em Saúde Coletiva da Universidade Federal de Juiz de Fora.

\section{Metodologia}

Optou-se, para a presente pesquisa, por uma abordagem metodológica qualitativa, com estudo descritivo exploratório. O campo do estudo foi um município que faz parte da Zona da Mata Mineira, na regiāo sudeste do estado de Minas Gerais. Os cenários escolhidos para o presente estudo foram os dois serviços de acolhimento temporário existentes no município, um destinado às mulheres e o outro destinado aos homens, que oferecem leitos para pernoite.

As técnicas utilizadas para a obtenção dos dados foram as entrevistas individuais com roteiro norteador semiestruturado, totalizando 20 entrevistas, que foram gravadas em áudio (MP3) após autorização pela assinatura do Termo de Consentimento Livre e Esclarecido e, em seguida, transcritas na íntegra, tornando-se material de análise. Outra técnica foi a observação e registro em diário de campo de conversas informais com os participantes da pesquisa. Serviu também para anotar as observaçôes de manifestaçôes comportamentais dos participantes em relaçáo aos pontos investigados pela pesquisa. Além disso, foram realizadas reuniôes com os gestores das secretarias de Saúde e de Desenvolvimento Social para esclarecimentos sobre como os serviços públicos são organizados para atender à demanda da população pesquisada.

Participaram voluntariamente das entrevistas 20 pessoas em situaçáo de rua e maiores de 18 anos, sendo 14 homens e seis mulheres. A pesquisa foi amplamente divulgada nos albergues e foram entrevistadas as pessoas que manifestaram interesse em participar. Por se tratar de pesquisa qualitativa, as entrevistas foram realizadas até obter-se saturação em relação ao conteúdo manifesto pelos participantes. Após essa constatação, duas outras entrevistas foram realizadas para confirmação da saturação das informaçôes.

Foram excluídas da pesquisa as pessoas que estiveram sem condiçôes cognitivas para responderem as perguntas propostas pela entrevista, em abuso de álcool e/ou outras substâncias psicoativas. Com a finalidade de preservar o sigilo dos participantes, estes foram identificados pela letra $\mathrm{E}$, seguida pelos números arábicos consecutivos, em ordem crescente, de acordo com o número de entrevistados (E1 a E20). 
Os dados foram interpretados à luz da hermenêutica dialética, seguindo os seguintes momentos: de ordenação dos dados, classificação dos dados e relatório final, conforme Minayo (2014) propôs. A organização dos dados permitiu estabelecer uma identificação do material coletado no campo de estudo, através da transcrição das entrevistas e leitura preliminar do material. $\mathrm{O}$ momento da classificação dos dados foi realizado a partir da leitura flutuante das entrevistas, com o objetivo de reconhecer as ideias centrais sobre o objeto de estudo, encontrando-se, assim, os núcleos de sentido que foram analisados. Para o presente artigo, destacam-se os núcleos de sentido: "motivos para procurar os serviços de saúde", "quando não procura os serviços de saúde", "serviços de saúde procurados, como ocorre seu acesso e como é o atendimento" e "dificuldades no acesso".

Após a identificação dos núcleos de sentido, os fragmentos das falas (unidades) relacionados a cada núcleo de sentido foram organizados em um quadro de análise (quadro 1), conforme proposta de Alencar, Nascimento e Alencar (2012).

Quadro 1. Análise das entrevistas

\begin{tabular}{|l|l|l|l|l|l|}
\hline \multicolumn{1}{|c|}{ Núcleos de sentido } & E1 & E2 & E(...) & E20 & $\begin{array}{c}\text { Síntese } \\
\text { horizontal }\end{array}$ \\
\hline Motivos para procurar os serviços de saúde & & & & & \\
\hline Quando não procura os serviços de saúde & & & & & \\
\hline $\begin{array}{l}\text { Serviços de saúde procurados; como ocorre } \\
\text { seu acesso e como é o atendimento }\end{array}$ & & & & & \\
\hline Dificuldades no acesso & & & & & \\
\hline Síntese vertical & & & & & \\
\hline
\end{tabular}

Fonte: as autoras.

Após as unidades (falas) serem organizadas no quadro 1, foram analisadas a partir das sínteses horizontal e vertical de cada núcleo de sentido. Enquanto a síntese horizontal possibilitou identificar convergências, divergências, e complementaridades das falas de cada participante da pesquisa, a síntese vertical possibilitou a visualização da articulação dos núcleos de sentido para cada participante individualmente.

Uma nova leitura das sínteses foi realizada retomando as questóes que norteiam o estudo, seus objetivos e seu referencial teórico, possibilitando a constituição 
das categorias de análise. No presente artigo, destaca-se a categoria: "o acesso da população em situação de rua nos serviços de saúde: acolhimento e dificuldades enfrentadas".

A pesquisa foi submetida ao Comitê de Ética em Pesquisa da Universidade Federal de Juiz de Fora, sendo aprovada em 12 de maio de 2017, através do parecer número 1.913.094.

\section{Resultados e Discussão}

Os entrevistados possuíam entre 25 e 68 anos. Em sua maioria, de cor preta, com ensino fundamental incompleto. $\mathrm{O}$ tempo que estavam em situação de rua variava entre dois e 31 anos.

A idade é um ponto que merece atenção. Segundo dados do diagnóstico da população em situação de rua no município da pesquisa, realizado em 2016, 25\% das pessoas em situação de rua tem acima de 50 anos (JUIZ DE FORA, 2016). Rinco, Lopes e Domingues (2012) afirmam que o envelhecimento é um processo que envolve questóes biológicas, psicológicas e sociais que podem tornar os idosos mais vulneráveis. A fragilidade do corpo, a manifestação de doenças crônicas, a dificuldade de locomoção e o distanciamento dos familiares são fatores que interferem na qualidade de vida dessa população. Ter acesso facilitado aos diversos serviços públicos, incluindo os de saúde, é essencial.

Os entrevistados E1, E4 e E12 estão nas ruas há muito tempo (18, 30 e 14 anos, respectivamente). Além da idade, carregam o peso de vários anos de alimentação incerta, de busca por água potável, de trabalho informal, de distanciamento das famílias, de preconceito, de violência e de dificuldade no acesso aos serviços públicos, causando impacto à saúde física e mental.

Outra questão que merece atenção é a racial. A cor da pele é um marcador importante para a compreensão das desigualdades sociais. Inúmeras são as desvantagens para quem nasce com a pele preta. Tanto a baixa escolaridade quanto o tempo de permanência nas ruas são fatores observados que podem estar relacionados com a cor da pele. Há uma grande diferença entre pessoas brancas e negras em relação aos trabalhos em que são empregadas, aos salários que recebem e também em relação ao acesso à educação, à saúde e outras políticas públicas (ROCHA, 2016; VOLOCHKO; VIDAL, 2010). 
Dada a caracterização da população pesquisada, o acesso aos serviços de saúde foi analisado a partir de quatro núcleos de sentido: "motivos para procurar os serviços de saúde", "quando não procura os serviços de saúde", "serviços de saúde procurados, como ocorre seu acesso e como é o atendimento" e "dificuldades no acesso".

\section{Motivos para procurar os serviços de saúde}

Os serviços de saúde eram acessados pelos entrevistados, na maioria das vezes, a partir de circunstâncias que interferiam no dia a dia da vivência nas ruas, como doenças ou agravos que impossibilitavam ou reduziam a mobilidade e outras ações para a sobrevivência. Eram acessados por esta população os serviços de urgência e emergência por atenderem a demanda espontânea, sem necessidade de encaminhamento de outros serviços.

As falas de alguns dos participantes ilustravam problemas como: dores na coluna, problemas nas pernas e alteração na visão.

[...] aí você chegou num ponto da história que é uma peleja. Eu tenho uma doença dessas que passa de pai para filho. É um negócio de má circulação e minha perna às vezes fica do tamanho de um poste. Por causa disso também deu uma ferida na minha perna que nunca melhora. Tá aqui aberta. Eu sempre tenho que fazer curativo (mostrou o curativo na perna). Por causa disso eu sempre tenho que procurar o médico. Além do meu problema na perna, também tenho um problema na coluna (E1).

Eu operei o olho [por catarata]... eu fiquei sete anos lá [fila para cirurgia eletiva]. Inclusive agora vai ficar ruim para o pessoal... porque o que aconteceu lá não dá para entender... eu ficar sete anos para operar uma vista (E4).

As informações corroboram o que Rosa, Cavicchioli e Brêtas (2005) perceberam em sua pesquisa: os serviços de saúde foram procurados por essa população, principalmente quando havia comprometimento da vida na rua, do trabalho, com impedimento da locomoção, como fraturas e lesôes nas pernas.

Vivenciar a situação de rua depende, muitas vezes, de funções orgânicas básicas, como mobilidade e visão. Conseguir deslocar-se de um ponto a outro da cidade e enxergar bem o que acontece ao redor são fatores essenciais para facilitar o dia a dia nas ruas. Dores na coluna, úlceras nas pernas e nos pés, como mencionadas por E1, atrapalhavam sua locomoção. A baixa visão, revelada por E4, atrapalhava no seu trabalho, já que era artesão, e também na sua segurança.

Associadas às vulnerabilidades, as doenças respiratórias apareceram nas falas de muitos entrevistados: 
Estava com muita febre e o corpo doendo. Era pneumonia. Mas graças a Deus eu estou melhorando (E12).

Todo ano me dá pneumonia. Além disso eu estou com tuberculose hoje em dia (E19).

Figueroa-Muñoz e Ramon-Pardo (2008) apontam que, além de um aumento de risco para a incidência da tuberculose, a situação de rua representa também um aumento de desfechos negativos da doença. As iniquidades vivenciadas pelas pessoas em situação de rua provocam a falta de proteção do corpo às variaçóes climáticas, principalmente ao frio. Não ter roupas adequadas para enfrentar as baixas temperaturas, a dificuldade para manter as roupas secas e limpas, dormir no chão, enfrentar chuvas e ventos relacionam-se com o risco das doenças respiratórias, como a pneumonia e, por extensão, a tuberculose.

Os autores ressaltam que o tratamento da tuberculose para as pessoas em situação de rua é um desafio quando comparado ao tratamento da população em geral. Isso porque verificou-se uma baixa adesão, além das complicaçôes provocadas pela má nutrição e comorbidades (FIGUEROA-MUÑOZ; RAMON-PARDO, 2008).

É importante considerar que alguns serviços relatados pelos participantes desta pesquisa ainda tinham dificuldades para encaminhar de forma efetiva determinados casos, como revelou E8:

Eu estava era com suspeita de tuberculose. Falaram pra eu ir para a casa me tratar. Me deram a receita e eu peguei os medicamentos. Pra casa? Vê se pode? Eu falei com a doutora que meu caso até podia não ser grave, não ser tuberculose... mas se eu voltasse pra rua, iria agravar. Época de frio, né? Fora que como eu não tinha jeito de guardar os remédios, eu poderia até perder. Já perdi! E foi dito e feito! Eu piorei (E8).

Embora E8 tenha informado à profissional de saúde sobre a particularidade de seu contexto, sendo explícito em relação ao fato de que muito provavelmente não teria condições de realizar o tratamento de maneira adequada, por estar vivenciando a situaçáo de rua, o encaminhamento do tratamento náo pareceu ter considerado seu posicionamento, sua demanda.

A falta de adesão ao tratamento da tuberculose, assim como de outras questóes de saúde, possui multicausalidade. Além da falta de compreensão por parte de certos serviços de saúde sobre o contexto dos pacientes, algumas situaçóes ocasionadas pela vivência nas ruas podem interferir na regularidade em que a medicação é tomada, que deve ser diária, ou até mesmo propiciar a interrupção do tratamento, como a alimentação inadequada e o abuso de substâncias psicoativas. Os medicamentos não 
permanecerem sob o cuidado do doente é outro fator de interferência do tratamento, já que na dinâmica das ruas é comum acontecer o roubo de pertences pessoais e até mesmo o recolhimento destes pertences pelo poder público (BRASIL, 2016).

Alguns participantes da pesquisa relataram doenças crônicas, como a epilepsia, a infecção por HIVIAIDS, a hipertensão e a anemia falciforme. Porém, apesar de conhecerem suas condiçôes crônicas, não faziam o acompanhamento ou iniciaram o acompanhamento e não deram prosseguimento:

Eu tenho problema de epilepsia... aí de vez em quando eu passo mal. Já tive muita crise (E9). Aí sobre a hipertensão eu queria falar que a gente não é acompanhado pelo médico. Não tem acompanhamento. Já me falaram que essa doença tem que ter consulta sempre... para saber como é que está... porque tem um monte de outra doença que está associada a essa aí (E4).

Eu também já fui no médico do Morro da Glória, onde era o Palácio da Saúde, para cuidar dessa minha doença que eu já falei [infecção por HIV]. Eu estava até tomando o remédio, mas aí eu parei de tomar o remédio também (E6).

Para anemia falciforme eu não faço o tratamento direito e também não procuro o serviço de saúde por causa disso, não (E19).

Campos (2016) observou que quanto maior a vulnerabilidade nos setores social, educacional e do trabalho, maior a prevalência de doenças crônicas. Nesse sentido, pode-se inferir que a população em situação de rua, devido aos diversos aspectos de vulnerabilidade que sofre, está sujeita a uma alta prevalência de doenças crônicas. Entretanto, a procura pelos serviços de saúde ocorre, em sua maioria, devido à agudizaçáo de tais doenças e/ou comorbidades que prejudicam a vivência na rua, e não para o seu acompanhamento. Os entrevistados desta pesquisa, por exemplo, procuraram pelos serviços de saúde, na maioria das vezes, por causa das doenças oportunistas, no caso da Aids, e pelas crises epilépticas, manifestando dificuldades para manter o acompanhamento de tais doenças.

Campos e Souza (2014) perceberam que muitas são as dificuldades para manter o acompanhamento de doenças crônicas. Dentre elas estão: a forma de organização dos serviços de saúde, as filas e a demora para agendar as consultas. Além disso, as autoras também fizeram a reflexão de que as pessoas que estão na rua possuem outras prioridades que não a saúde, como a preocupação com o local para dormir e dificuldades para obter alimentação.

Outra condiçẫo crônica que se destacou nesta pesquisa foi o uso prejudicial de álcool e/ou outras drogas. Foram mencionados também casos de pancreatite e complicaçôes no fígado, doenças relacionadas ao uso prejudicial de álcool: 
Olha... eu sou dependente químico. No CAPS eles tão me ensinando isso. Eu nunca imaginei que ia parar... mas eu vejo gente que conseguiu... então é possível. Vou falar com você que crack tem um tempo que eu não pego mais não. Mas um baseado não tem jeito... eu não aguento, não. Eu tenho que fumar (E2).

Eu faço meu checkup todo ano. Na verdade eu andei bebendo bastante e isso afetou meu pâncreas e meu fígado. Por isso que eu procuro o checkup. Mas faz parte (E11).

Mota, Ronzani e Moura (2016) observaram que há na sociedade uma concepção moral sobre o uso de álcool e outras drogas que estigmatiza, exclui e promove diversos preconceitos em relação aos usuários de substâncias psicoativas. Muitos serviços de saúde compartilham desta concepçâo. Os autores ressaltaram que, apesar de as pessoas em situação de rua serem vistas como desprovidas de recursos internos e externos para lidar com a dependência, possuem uma abertura para tentarem sair das ruas e lidarem com o uso de drogas.

Para tanto, é imprescindível a oferta de acompanhamento através de uma rede integrada com o Consultório na Rua (CnaR), que se aproxime da população de rua, capacitada para promover um atendimento sem discriminação, associado às práticas educativas e também de redução de danos, que leve em conta as singularidades desse grupo que não possui uma rede familiar de suporte e que vivencia inúmeras vulnerabilidades. No município da pesquisa, o trabalho desenvolvido pelo Centro de Atenção Psicossocial (CAPS) foi mencionado pelos participantes como importante e humanizado.

\section{Quando náo procura os serviços de saúde}

Os serviços de saúde geralmente não eram procurados em situaçóes consideradas pelos participantes da pesquisa como banalidades ou ocorrências pequenas, como dores de cabeça, tontura, zumbido nos ouvidos, dores nas costas e tosse:

Outra coisa que também sempre dá é dor de cabeça, zumbido no ouvido, tonteira... Às vezes eu acho que vou desmaiar. Já me disseram que pode ser falta de água ou falta de comida. Nesse calor... O calor tá de matar. Não é fácil. Se a gente não come e não bebe água fica complicado... mas, também não tem como procurar o médico só por causa disso (E1).

Olha...nesse tempo que eu estou na rua, graças a Deus nunca precisei, não. É o que eu disse... eu não vou procurar serviço de saúde por causa de uma tosse. Isso é bobeira. Ainda mais a gente que pega friagem toda hora... fica gripado e tossindo mesmo. Isso é normal (E13).

Como as pessoas em situação de rua enfrentam algumas barreiras para acessar os serviços de saúde, estes eram procurados em último caso, quando a necessidade 
de saúde ultrapassava os limites da dor ou interferia diretamente na sobrevivência. Muitas vezes, dores de cabeça, fraqueza e dores no corpo, que são considerados motivos banais para a procura dos serviços de saúde, podem refletir a manifestação ou complicações de outras doenças, como doenças crônicas, que necessitam de acompanhamento (CAMPBELL et al., 2015).

As dificuldades relatadas pelos entrevistados para lidar com as doenças crônicas chamaram a atenção para a atuação da Atenção Básica (AB) para a população em situação de rua do município, já que esta possui papel essencial na prevenção de doenças crônicas, no seu tratamento e acompanhamento. Tornou-se importante então verificar quais eram os serviços de saúde mais procurados pela população estudada. A AB encontrava-se entre eles? Como ocorria este acesso?

\section{Serviços de saúde procurados, como ocorre seu acesso e como é o atendimento}

$\mathrm{O}$ acesso aos serviços de saúde foi retratado na figura 1 .

Figura 1. Serviços de saúde acessados pela população em situação de rua do município de Juiz de Fora, MG, 2018.

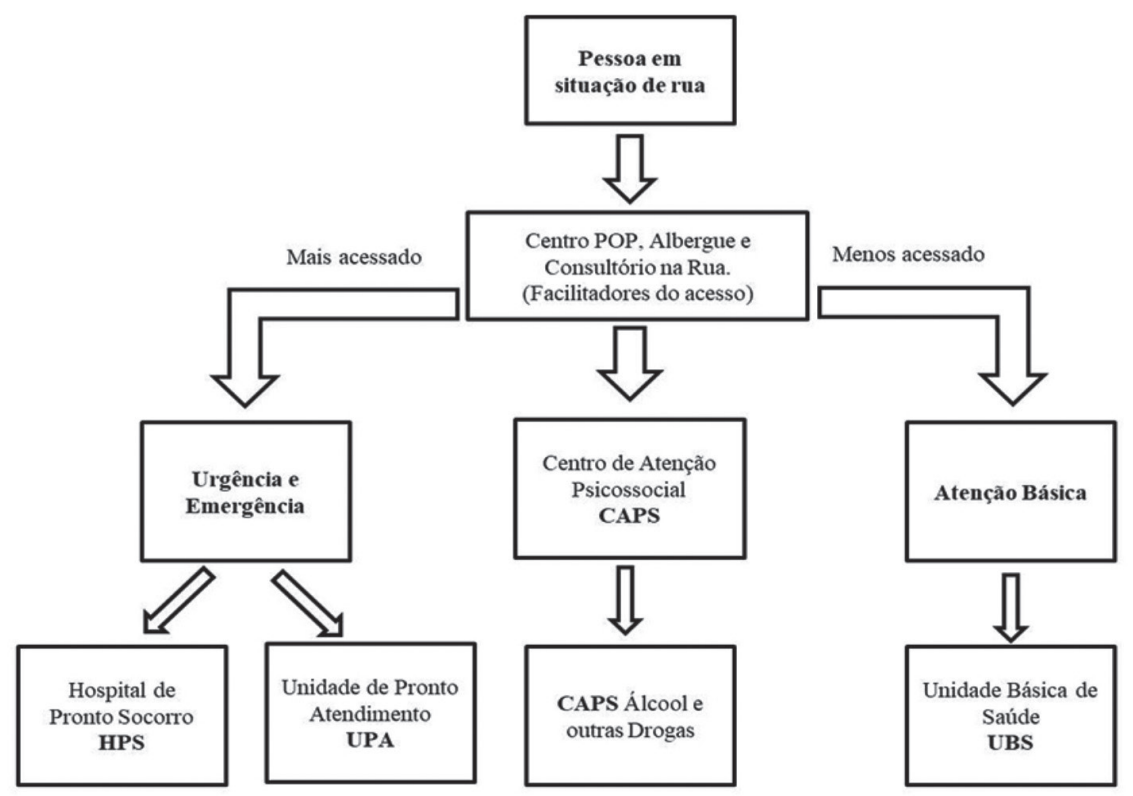

Fonte: As autoras. 
Os serviços mais acessados eram os de urgência e emergência: o Hospital de Pronto Socorro (HPS) e a Unidade de Pronto-Atendimento da Regional Leste de Saúde (UPA Leste).

Um dia eu desmaiei na rua e não era a primeira vez. Eu vivia com mal-estar, um calorão, enjoo... Eu resisti, mas fui na Regional Leste (E15).

Procuro a saúde quando estou com crise (de epilepsia). Mas aí não sou eu que procuro. Quem está do meu lado é que procura pra mim. Chamam o SAMU e eu vou (E3).

Aguiar e Iriart (2012) reconhecem, em seu estudo, a mesma situação no acesso aos serviços de saúde: os serviços de urgência e emergência foram os mais procurados. Como eram as situaçôes de urgência e emergência que mais levavam os entrevistados a buscarem pelos serviços de saúde, foi possível compreender a procura pelo HPS e pela UPA. O HPS é o destino do Serviço de Atendimento Móvel às Urgências (SAMU), recurso utilizado pelas pessoas entrevistadas, como pôde ser observado nos relatos. Já a UPA funciona todos os dias da semana, ininterruptamente, com estrutura física e profissional para resolver grande parte das urgências e emergências. Ficou evidente que o acesso acontecia porque os entrevistados eram levados a esses serviços de saúde, na maioria das vezes, com quadros de rebaixamento da consciência, quando estavam com determinados quadros de crise. Sem dúvidas, o acesso à $A B$ poderia oferecer a prevenção de tais quadros.

O acesso aos outros serviços de saúde, como CAPS, e outros atendimentos especializados acontecia mais facilmente quando havia a intervenção do Centro de Referência Especializado para População em Situação de Rua (Centro POP), do CnaR ou do albergue, que são equipamentos com equipe capacitada para atender essa populaçáo. A maioria dos entrevistados, quando passava por alguma necessidade de saúde, procurava em primeiro lugar estes equipamentos:

Quando eu tenho um problema de saúde... ou eu venho no albergue ou no POP. Eu já venho neles para não ter problema. É o que eu acabei de comentar... se você vai sozinho no hospital, dá sempre problema... sempre! E com eles levando... pode até atender frio, demorar, fazer alguma sacanagem... mas de qualquer jeito tem que atender, né? Tem que dar pelo menos a receita do remédio que você precisa. Agora... você sozinho... falam que você não tem nada... ou falam que não tem médico para te atender... aí você vai fazer o quê? Você fica esperando duas, três horas e perdeu o seu tempo! E a pessoa doente, sentindo alguma coisa, tem que ter atendimento, né? (E4).

O entrevistado E3 era usuário do CAPS e afirmou que procurava o serviço mesmo para problemas que não envolviam atenção psicossocial: 
Serviço de Saúde? Olha... o negócio é o seguinte... ou eles vêm até nós, ou então eu peço para eles ligarem para o CAPS... porque eu faço tratamento no CAPS. Prefiro procurar o CAPS mesmo, porque lá eu sei que eles vão dar um jeito. O CAPS é a melhor coisa... tudo de bom... só eles mesmo (E3).

Quando o funcionamento da rede de atenção à saúde ocorre de maneira adequada, todos os níveis de atenção são utilizados de acordo com o que cada caso requer. A AB deveria ser um serviço de referência.

Nas falas dos participantes da pesquisa, a $\mathrm{AB}$ é representada pelo CnaR e pelas UBS. O CnaR é um dispositivo da AB para os cuidados com a população em situação de rua, estabelecido pela Política Nacional de Atenção Básica (2011). Ele é composto por equipe multiprofissional e atua de forma integrada às UBS, ao CAPS, aos serviços de urgência e emergência e aos outros pontos da rede de atenção à saúde. O CnaR possui papel primordial para o acesso das pessoas em situação de rua aos serviços de saúde e foi relatado na presente pesquisa como um serviço muito utilizado:

Tem também o Consultório de Rua que vem aqui na porta toda segunda e também é muito legal... o pessoal é muito gente boa. Muita gente legal que só incentiva mesmo (E2).

Eu nem procuro médico, nem procuro nada. Eles do albergue, do Consultório que passa aqui em frente já arrumaram médico pra mim (E6).

No município da pesquisa, o CnaR, com a composição da equipe de acordo com a modalidade II (enfermeiro, técnico de enfermagem, psicólogo, assistente social), passava pelos albergues uma vez por semana, verificando as necessidades de saúde dos usuários e realizando encaminhamentos. Seu atendimento foi elogiado por todos os entrevistados que o utilizaram. Entretanto, há apenas uma equipe do CnaR em atuação, que não consegue lidar com todas as demandas e não consegue cobrir a maior parte do município. Nesse sentido, é preciso pensar na possibilidade de ampliação do serviço para alcançar mais pessoas em situação de rua, e também na implantação da modalidade III, que poderia solucionar in loco muitas necessidades de saúde dessa população, já que esta modalidade possibilita a presença do profissional médico. Tal ampliação do CnaR possibilitaria ações mais abrangentes de promoção da saúde e prevençáo de doenças, e contribuiria com a demanda de adesão ao tratamento de doenças crônicas e outras doenças que exigem tratamento regular, como a tuberculose.

Além do suporte do CnaR, seria importante que essas pessoas também tivessem autonomia para chegarem à UBS quando necessitarem. Apenas três dos 
entrevistados mencionaram terem sido atendidos na UBS, e através da mediação do CnaR e do albergue:

Eu procuro a assistente social do albergue. Aí sim! Ela costuma ajudar muito. Marca consulta pra mim lá no postinho na Vila Ideal (E7).

Pra mim... tudo que eu tenho eu procuro o Consultório na Rua. Primeiro eles me levaram pro postinho da Vila Ideal... por causa da pneumonia e da tuberculose (E19).

A localização da UBS que recebia os casos encaminhados pelo CnaR era distante dos principais locais de aglomeração das pessoas em situação de rua do município e ofertava apenas duas vagas semanais, que eram insuficientes, sobretudo quando se consideram os casos de doenças crônicas, que necessitam de acompanhamento, além das condiçôes de saúde que se agravam com a permanência nas ruas.

A insuficiência de vagas foi abordada em reuniôes com membros da gestão da secretaria de saúde do município e apareceu no relato de E15:

Eu sei que quando as pessoas precisam de alguma coisa, o pessoal da saúde que passa aqui em frente de carro consegue vaga. Mas eu sei também que demora muito. Já ouvi dizer que no posto de saúde são só duas vagas por semana para gente (E15).

Uma das entrevistadas expressou sua vontade de realizar o exame ginecológico preventivo, entretanto, não sabia qual serviço de saúde deveria procurar e apontava a dificuldade para conseguir vaga na $\mathrm{AB}$ :

Às vezes eu tenho vontade de fazer um preventivo... essas coisas. Mas eu não sei direito como fazer. Eu acho que é só chegar no HPS, na Regional Leste e pedir ou será que tem que ir no postinho? Aí é mais difícil conseguir vaga (E17).

Sem o acesso às UBS, os serviços de saúde eram procurados apenas quando havia o agravo de doenças, muitas vezes em casos que exigiam tratamentos de alta densidade e de alto custo para o município. A pessoa que estava em situação de rua, além de ter que lidar com o estado da doença, tinha que lidar também com o medo da morte, com o estresse, com a perda do controle do próprio corpo, e tudo isso sem poder contar com uma rede de suporte afetivo que lhe ajudasse a enfrentar este momento delicado.

Dúvidas como as de E17, sobre qual serviço de saúde procurar, também apareceram nos relatos de outras pessoas entrevistadas:

É difícil para marcar consulta, para marcar retorno e assim... eles mandam eu caçar o posto do meu bairro. E qual que é o posto do meu bairro? Não tem, né? Porque eu estou na rua (E16). 
Vale ressaltar que pela PNPSR (2009), o acesso amplo, simplificado e seguro aos serviços e programas que integram as políticas públicas de saúde deve ser garantido às pessoas em situação de rua. A restrição de UBS e do número de atendimentos para esse grupo populacional promove a iniquidade e caminha no sentido contrário à PNPSR.

Expandir o atendimento das pessoas em situação de rua para todas as unidades básicas de saúde é prioritário. De acordo com a Política Nacional de Atenção Básica (2011), é importante a vinculação do indivíduo a uma UBS para facilitar o desenvolvimento de sua conexáo com os serviços de saúde, para favorecer o seu acompanhamento, e para possibilitar que o profissional de saúde conheça sua realidade (BRASIL, 2011). Essas açôes são fundamentais para o desenvolvimento do cuidado integral. Muitas pessoas em situação de rua dormiam em um mesmo bairro da cidade por muitos anos e poderiam estar vinculadas à UBS desse bairro. Por outro lado, também existiam as pessoas que não permaneciam em um mesmo lugar durante muito tempo, daí a necessidade de flexibilização, permitindo também o acesso às pessoas em situação de rua que não eram do território da UBS. O acesso a uma única UBS, como normatizado pelo município, não é capaz de atender à população de rua, que é um grupo socialmente vulnerável, que convive com inúmeras particularidades da vivência nas ruas. Além disso, a expansão do acesso às UBS fortalece o cuidado integral, já que contribui para o funcionamento da Rede de Atenção à Saúde.

O Plano Diretor da Atenção Primária à Saúde (PDAPS) implantado em 2014 no município, teve como objetivo a melhoraria dos processos da $\mathrm{AB}$ e sua normalização à luz da gestão do cuidado, qualificando os profissionais de todas as Unidades Básicas de Saúde (UBS) do município (JUIZ DE FORA, 2014). O momento é propício para fortalecer os cuidados da $\mathrm{AB}$ para a população em situação de rua.

Em relação à forma com que eram acolhidos e atendidos nos serviços de saúde, dos 20 entrevistados, 11 disseram que eram bem atendidos ou tratados "normalmente" nos serviços de saúde. Entretanto, ao mesmo tempo que declararam serem bem atendidos, alguns revelaram experiências que apontaram o contrário:

Já fui no HPS, na Regional Leste... principalmente quando dá convulsão. Aí eu fico no soro lá. Já fiquei uns quatro dias internado... acho que foi por aí. Isso mesmo. Me trataram bem lá... só que assim... o pessoal só olha a gente em determinado horário...não conversa... não tira dúvida... só olha mesmo. Parece que tem medo da gente. Às vezes a gente quer perguntar alguma coisa e nem consegue, eles mal olham na nossa cara. Mas eles me trataram muito bem. Isso deve ser porque eles têm muito trabalho (E3). 
Ainda sobre as experiências de atendimento, metade dos entrevistados revelou situações em que sofreram preconceito:

Aí na hora que você chega lá no médico e abre a boca para falar que é morador de rua, aí...
você vê que esfriou. Aí ele já não te atende direito, manda você embora e pronto. Você
percebe a diferença de atendimento na hora. Você percebe que o próprio médico esfriou.
Geralmente um colega da rua comenta o que aconteceu com outro... de desrespeito no
atendimento do médico... e a gente fica sabendo um monte de caso (E4).
E quando a gente está mal arrumado, sujo, parece que o tratamento é diferente. A gente
vai sendo deixado de lado... as pessoas só falam com a gente o que é extremamente ne-
cessário (E20).

Farias et al. (2014) afirmam que são recorrentes os sentimentos de vivência de preconceito e discriminação nos serviços de saúde. A vivência de situações preconceituosas e segregadoras nos serviços de saúde demonstram que ainda há um caminho longo a ser percorrido para a implantaçáo da PNPSR (2009). É preciso que sejam ampliadas as estratégias de desmistificação das questôes que geram o preconceito. Nesse sentido, atividades de aproximação dos trabalhadores do setor público à população em situação de rua, através rodas de conversas e outros espaços de interação, por exemplo, podem produzir efeitos positivos.

\section{Dificuldades no acesso}

A dificuldade para o acesso mais marcante que apareceu nas entrevistas foi a necessidade de comprovação de residência para o atendimento nas UBS do município que não estavam encarregadas de atender as pessoas em situação de rua. Seguindo a mesma lógica, essas pessoas encontraram obstáculos também para conseguir medicamentos por falta da renovação da receita ou por falta de documentação.

Tem o pessoal de bairro nos postos de saúde, certo? Mas é difícil marcar porque fala que tem que comprovar que mora no bairro do posto... mas a gente mora na rua, né? Não tem como comprovar (E2).

Para pegar medicamento é que é muita dor de cabeça. Precisa da receita e do documento, né? Aí com esse meu problema da epilepsia... às vezes eu acordo e num estou com o documento. Na rua também a gente perde... Às vezes quando eu estou na rua dá uns problema assim de perder documento. É dor de cabeça (E4).

Rodrigues (2016) declara que a garantia de muitos direitos passa pelo "pressuposto burocrático" da posse de um domicílio. Isto é, exige a existência de um vínculo que a pessoa em situação de rua não possui, o que gera um distanciamento da 
condição de cidadania. $\mathrm{O}$ autor também apontou que as pessoas que estão na rua não possuem o direito à propriedade resguardado, já que seus pertences, incluindo documentos, são constantemente violados, inclusive pelo poder público, e isso acarreta a impossibilidade de apropriaçáo de outros direitos.

A falta de documentaçáo foi um problema concreto que muitas vezes impediu o acesso desse grupo aos serviços de saúde, assim como a dispensação de medicamentos de uso controlado, já que era preciso apresentar documento de identidade e comprovante de endereço para a confecção do Cartão SUS. Para resolver tal situação, a Portaria no 940 do Ministério da Saúde (BRASIL, 2011), regulamenta que o Sistema Cartão Nacional de Saúde dispense a comprovação de endereço domiciliar da população em situação de rua. Entretanto, a portaria ainda a é pouco conhecida e seu cumprimento ainda é uma expectativa.

\section{Considerações finais}

A experiência de dar voz às pessoas em situação de rua para compreender suas vivências no acesso aos serviços de saúde foi única e promoveu inúmeras reflexôes sobre as dificuldades cotidianas que elas enfrentam e sobre o quanto o sistema de saúde do município de Juiz de Fora ainda tem que avançar.

Dos motivos para a procura pelos serviços de saúde, foram indicados com maior frequência os problemas que interferem no cotidiano das ruas, quando já não era possível aguentar a dor, ou já não era possível realizar as atividades diárias. Assim, dores de cabeça, tontura e dores no corpo, que podem indicar condiçóes crônicas, foram consideradas motivos insignificantes para a procura pelos serviços.

$\mathrm{O}$ acesso à rede de assistência à saúde pela $\mathrm{AB}$ tinha uma atuação expressiva do CnaR, entretanto, uma única UBS era responsável pelos atendimentos da população em situação de rua do município. O número de vagas foi apontado como insuficiente, e a relação dos entrevistados com as doenças crônicas permitiu inferir que ainda há uma fragilidade da $\mathrm{AB}$ para o público da pesquisa.

É imprescindível possibilitar às pessoas que estão nas ruas o acesso aos serviços de saúde, de acordo com o princípio da universalidade, sem ter que lidar com as barreiras que ainda hoje encontram; que possam vivenciar a equidade nas açôes de saúde e que consigam acesso integral a todos os níveis de atenção, de forma articulada, visando não somente curar as doenças, mas preveni-las e também 
promover a saúde. Possibilitar o acesso a um direito fundamental como o direito à saúde é possibilitar, em parte, a transformação da realidade das pessoas que mais precisam usufruir desse direito.

Muitos ainda são os desafios a se enfrentar, a partir da compreensão de que é necessário oferecer um atendimento de qualidade, acessível a todos, sem preconceitos, com profissionais capacitados e sensíveis à situação social do grupo deste estudo. A saúde é direito de todos. Que este direito se cumpra na realidade daqueles que mais precisam. ${ }^{1}$

\section{Referências}

AGUIAR, M. M.; IRIART, J. A. B. Significados e práticas de saúde e doença entre a populaçáo em situação de rua em Salvador, Bahia, Brasil. Cadernos de Saúde Pública. Rio de Janeiro, v. 28, n. 1, p. 115-124, jan. 2012.

ALENCAR, T. O. S.; NASCIMENTO, M. A. A.; ALENCAR, B. R. Hermenêutica dialética: uma experiência enquanto método de análise na pesquisa sobre o acesso do usuário à assistência farmacêutica. Revista Brasileira de Promoção da Saúde. Fortaleza, v. 25, n. 2, p. 243-250, abrjun. 2012.

ASSIS, M. M. A.; JESUS, W. L. A. Acesso aos serviços de saúde: abordagens, conceitos, políticas e modo de análise. Ciência \& Saúde Coletiva. Rio de Janeiro, v. 17, n. 11, p. 2865-2875, 2012.

BARATA, R. B. et al. Desigualdade social em saúde na população em situação de rua na cidade de São Paulo. Saúde e Sociedade. São Paulo, v. 24, n. 1, p. 219-232, 2015.

BOVE, C.; FIGUEIREDO, G. A política nacional para a população em situação de rua: processo e participação. In: GRINOVER, A. P. et al. (Org.). Direitos fundamentais das pessoas em situação de rua. 2 ed. Belo Horizonte: Editora D’Plácido, 2016. p. 421-428.

BRASIL. Constituição da República Federativa do Brasil, 1988. Brasília: Senado Federal, Centro Gráfico, 1988. 292 p.

. Decreto no 7.053, de 23 de dezembro de 2009. Institui a Política Nacional para a População em Situação de Rua e seu Comitê Intersetorial de Acompanhamento e Monitoramento, e dá outras providências. Diário Oficial da União, Brasília, DF, 24 dez. 2009a. Seção 1. p.16. Disponível em: <http://www.planalto.gov.br/ccivil_03/_ato2007-2010/2009/decreto/d7053. htm>. Acesso em: 20 ago. 2019.

. Portaria no 940, de 28 de abril de 2011. Regulamenta o Sistema Cartão Nacional de Saúde (Sistema Cartão). Diário Oficial da União, Brasília, DF, 29 abr. 2011. Seção 1, p.36. Disponível em: <http://bvsms.saude.gov.br/bvs/saudelegis/gm/2011/prt0940_28_04_2011. html>. Acesso em: 20 ago. 2019. 
- Ministério da Saúde. Política Nacional de Atençâo Básica. Brasília: Ministério da Saúde, 2011. (Série E. Legislação em Saúde). Disponível em: <http://189.28.128.100/dab/docs/ publicacoes/geral/pnab.pdf>. Acesso em: 20 ago. 2019.

. Ministério da Saúde. Síntese de evidências para políticas de saúde: adesão ao tratamento de tuberculose pela população em situação de rua. Brasília: Ministério da Saúde, 2016. Disponível em: <http://189.28.128.100/dab/docs/publicacoes/geral/pnab.pdf>. Acesso em: 20 ago. 2019.

CAMPBELL, D. J. T. et al. Primary health care needs and barriers to care among Calgary's homeless populations. BMC Family Practice, v. 139, n. 16, 2015.

CAMPOS, A. G. Qual a dor do morador de rua? Dissertação (Mestrado Profissional em Enfermagem) - Faculdade de Ciências em Saúde Albert Einstein, São Paulo, 2016.

CAMPOS A. G.; SOUZA M. P. F. Violência muda e preconceito: estratégias de uma equipe de saúde em defesa da cidadania da população em situação de rua. Boletim do Instituto de Saúde. São Paulo, v. 3, n. 14, p. 344-351, 2014.

COHN, A. A ofensiva raivosa no desmonte do SUS. Brasil Debate, Rio de Janeiro, p. 1-4, jun. 2016.

FARIAS, D. C. S. et al. Saberes sobre saúde entre pessoas vivendo em situação de rua. Psicologia e saber social, v. 3, n. 1, p. 70-82, 2014.

FIGUEROA-MUÑOZ, J. L.; RAMON-PARDO, P. Tuberculosis control in vulnerable groups. Bull World Health Organ, v. 9, n. 86, p. 733-735, 2008.

JUIZ DE FORA. Secretaria de Saúde. Plano Diretor da Atenção Primária em Saúde: projeto de implantação. Juiz de Fora, 2014. Disponível em: <https://www.pjf.mg.gov.br/secretarias/saude/ plano_diretor/docs/implantacao.pdf>. Acesso em: 20 ago. 2019.

LARA, L.; GUARESCHI, N. M. F.; BERNARDES, A. G. Reforma Sanitária e a privatização da saúde em um contexto. Psicologia \& Sociedade. Belo Horizonte, v. 2, n. 28, p. 360-368, 2016.

MINAYO, M. C. S. O desafio do conhecimento: pesquisa qualitativa em saúde. São Paulo: Hucitec Editora, 2014. 407 p.

MOTA, D. C. B.; RONZANI, T. M.; MOURA, Y. G. Tratamento e apoio psicossocial às pessoas em situação de rua usuárias de drogas. In: GRINOVER, A. P. et al. Direitos fundamentais das pessoas em situaçâo de rua. 2 ed. Belo Horizonte: Editora D’Plácido, 2016. p. 497-514.

PAIVA, A. B. et al. O Novo Regime Fiscal suas implicaçóes para a Política de Assistência Social no Brasil. In: INSTITUTO DE PESQUISA ECONÔMICA APLICADA. Nota Técnica. Brasília: IPEA, 2016, p. 3-34.

RINCO, M.; LOPES, A.; DOMINGUES, M. A. Envelhecimento e Vulnerabilidade Social: discussão conceitual à luz das políticas públicas e suporte social. Revista Temática Kairós Gerontologia. São Paulo, v. 6, n. 15, p. 79-95, dez. 2012. 
RIZZOTO, M. L. F. Nenhum passo atrás na conquista do direito à saúde. Saúde Debate. Rio de Janeiro, v. 40, n. 109, p. 4-7, abr-jun. 2016.

ROCHA, E. Cor e dor moral. In: SOUZA, J. A ralé brasileira: quem é e como vive. Belo Horizonte: Editora UFMG, 2016, p. 409-444.

RODRIGUES, I. A construção social do morador de rua: derrubando mitos. Curitiba: CRV, 2016. 98 p.

ROSA, A. S.; CAVICCHIOLI, M. G. S.; BRÊTAS, A. C. P. O processo saúde-doença-cuidado e a população em situação de rua. Revista Latino-americana de Enfermagem. São Paulo, v. 13, n. 4, p. 576-582, jul-ago. 2005.

VOLOCHKO, A.; VIDAL, N. P. Desigualdades raciais na saúde: mortalidade nas regióes de saúde paulistas em 2005. Boletim do Instituto de Saúde. São Paulo, v. 12, n. 2, p.142-154, ago. 2010.

\section{Nota}

${ }^{1}$ F. A. A. L. Valle contribuiu com a concepção e o delineamento das ideias, execução da pesquisa, análise dos dados e redaçáo do artigo. B. F. Farah orientou a pesquisa e contribuiu com a concepção e o delineamento das ideias, análise dos dados e redação do artigo. 


\section{Abstract}

Health of those who are in homeless situation: (in) visibilities in access to the Unified Health System

Access to the Unified Health System is prerequisite for the dignity of the homeless population, which, due to social vulnerability, is exposed to factors that interfere with health. Objective: to understand how the access to the Unified Health System in the perception of the homeless adults. Qualitative methodological approach, with exploratory descriptive study. The techniques used were: semi-structured individual interviews and observation and field diary. Twenty homeless people participated in the research. The information was analyzed in the light of Dialectic Hermeneutics. Access to health services occurred in urgent and emergency situations and in Basic Attention was limited, two weekly vacancies were offered to this population, in a single Basic Health Unit. The access takes place through the mediation of the social protection network or the Street Clinic, restricting the access of citizens to health services. There were barriers in accessing health services: need to present documents; proof of residence. There are many challenges. Health is everyone's right, and their access must be a reality.

> Keywords: homeless persons; access to health; health services. 